\title{
The Effects of Cocktail Anaesthesia on Blood Pressure*
}

\author{
A. GRACE WARREN \\ Medical Superintendent, Hay Ling C'hau Leprosarium, Hong Kong \\ and \\ PHYLLIS M. TAYLOR \\ Previously at Hay Ling Chau \\ Physician, S.L.R.S. Karigiri, South India
}

\begin{abstract}
In leprosy centres, the absence of a second trained doctor to give anaesthetics of ten limits the surgeon wishing to operate. "Cocktail anaesthesia", as described here, has proved to be useful in this and other situations, and is often preferred to general anaesthesia by those accustomed to administering it. Many different drugs have been used for this purpose. In this paper a method that has been found effective in Chinese patients is described, with details of observations that indicate its safety and adaptability.
\end{abstract}

\section{Introduction}

In leprosy patients, surgery is required most of ten for deformities of the hands, feet or face. Since trained staff are not always available, a method of anaesthesia that does not require constant skilled supervision is an advantage. Local anaesthesia and regional block have their advocates, but these methods may not in all cases render bearable the discomfort that results from the pressure of the tourniquet. If restlessness should occur at the critical time when the tendons are being sutured towards the end of the operation, then the consequences may be serious.

For the past 7 years, one of us (A. G. W.) has been using a type of lytic "Cocktail", modified from one previously used at Karigiri. With this form of anaesthesia, the patient sleeps deeply throughout the operation and retains no memory of the procedure, but keeps his normal protective reflexes. He usually awakens some 3 or 4 hours later, with no nausea, vomiting, headache or any of the other side-effects that may follow general anaesthesia. Because questions have been raised concerning the fall in blood pressure that occurs, a study was undertaken on the effects of Cocktail Anaesthesia on blood pressure.

\footnotetext{
* Received for publication 26 January, 1973.
} 


\section{Materials and Methods}

1. THE COCKTAIL (as given at Hay Ling Chau)

(a) Premedication

1. The night before the operation:

amylobarbitone (100 to $200 \mathrm{mg}$ ); with chlorpromazine (Largactil ) (50 to $100 \mathrm{mg}$ ) if the patient is apprehensive or is known to have been uncooperative. On the morning of operation day a light meal is given at least $4 \mathrm{~h}$ before the time fixed for operation.

2. Two hours before operation:

amylobarbitone $(200 \mathrm{mg})$ and phenergan $(25 \mathrm{mg})$ by mouth.

3. One hour before operation:

morphia $(10 \mathrm{mg})$ and hyoscine $(0.4 \mathrm{mg})$ by intramuscular injection.

\section{(b) Preparation of the Cocktail}

Between 20 and 30 minutes before beginning the actual operation, the Cocktail itself is prepared; this consists of: pethedine $(100 \mathrm{mg})$, chlorpromazine $(50 \mathrm{mg})$ and saline to $20 \mathrm{ml}$. (Note: distilled water or glucose may be used, though the latter may give a cloudy solution.)

\section{(c) Administration of the Cocktail}

In Chinese patients weighing about $50 \mathrm{~kg}, 8$ to $10 \mathrm{ml}$ of the mixture, administered intravenously, usually gives an analgesia of sufficient duration to enable the surgeon to perform such operations as foot-drop correction, lumbrical replacement, or triple arthrodesis of the ankle. In the elderly or the young, a smaller dose of morphia may be given as premedication and a smaller volume of the Cocktail. In an elderly subject, 2 or $3 \mathrm{ml}$ of the Cocktail is of ten sufficient for foot-drop correction. The maximum depth of sedation is attained in 20 to 30 min; if sedation is not adequate, a further dose of 2 to $5 \mathrm{ml}$ may be given, and repeated as required.

\section{(d) Post-operative care}

After the operation the patient is returned to the ward; his head should be turned to one side to help maintain the airway. Close supervision is not required, since the patient is rarely restless, and he will answer to his name in a few hours. If not roused, he may pass from post-operative haziness into normal sleep. There is no nausea, vomiting, or headache, and the appetite is unimpaired. Urinary retention is almost unknown.

\section{PATIENTS}

In this series all patients chosen for operation who would normally have been given "Cocktail Anaesthesia" were at first included; even those patients known to be, or to have been, addicted to "hard" drugs. However, those whose operation was of less than one hour's duration are excluded from this report, since insufficient data are available. The 77 patients included, comprise 69 men and 8 women, their ages ranging from 16 to 73 years.

\section{SCHEDULE OF OBSERVATIONS}

Blood pressure, pulse rate, respiration rate were recorded: (a) the day before surgery, (b) before sedation, (c) before anaesthesia, and then (d) every $10 \mathrm{~min}$ 
after the intravenous injection of the Cocktail until the patient was returned to the ward.

\section{Results and Discussion}

\section{BLOOD PRESSURE}

The maximum fall in systolic blood pressure, as compared with the recording taken the day before operation, is shown in Fig. 1. The patient who had a fall of $70 \mathrm{~mm} \mathrm{Hg}$ systolic had an initial blood pressure of 170/90. While he was under sedation his blood pressure was $100 / 70$. This apprehensive patient has a very labile blood pressure. In the majority of patients the fall in systolic blood pressure was not more than $30 \mathrm{~mm}$ (60 cases out of 77).

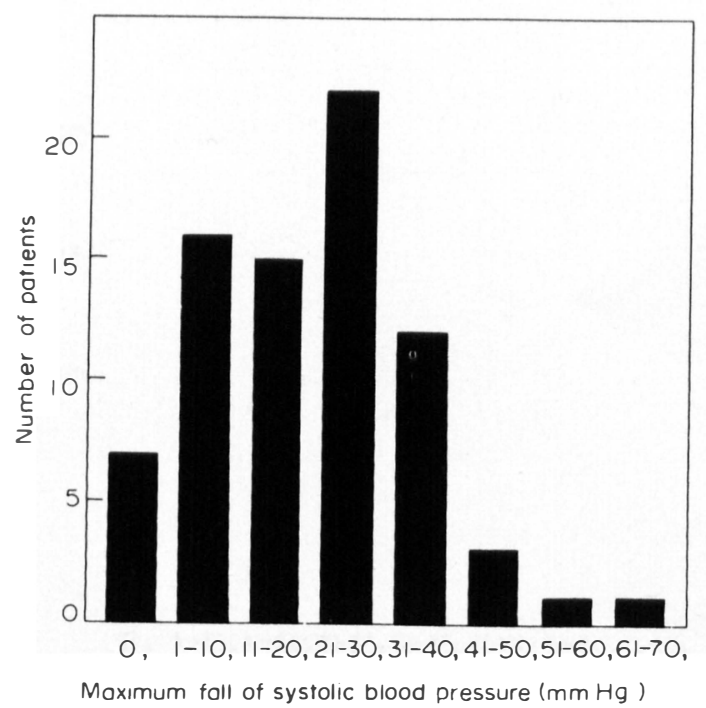

Iiig. 1. Maximum fall of systolic blood pressure, after the intravenous injection, as compared with the reading taken the day before operation.

Figure 2 shows that the maximum fall in blood pressure occurred most commonly within $30 \mathrm{~min}$ of the intravenous injection. Although 2 patients had a low blood pressure and a pulse pressure of less than $20 \mathrm{~mm} \mathrm{Hg}$, as shown in Fig. 3, they presented no other evidence of shock. Both had a pre-operative blood pressure of $100 / 70 \mathrm{~mm} \mathrm{Hg}$.

\section{PULSE}

The pulse rate is of ten raised before the operation, but usually settles af ter the premedication, and may slow more after the intravenous medication is given. In fact, it was noted that although the blood pressure fell markedly in a few patients, the pulse showed no compensatory rise (Fig. 4).

\section{RESPIRATION}

Patients who had rapid shallow respirations at the beginning of the operation usually breathed more slowly and more deeply within $15 \mathrm{~min}$. In no case did the 


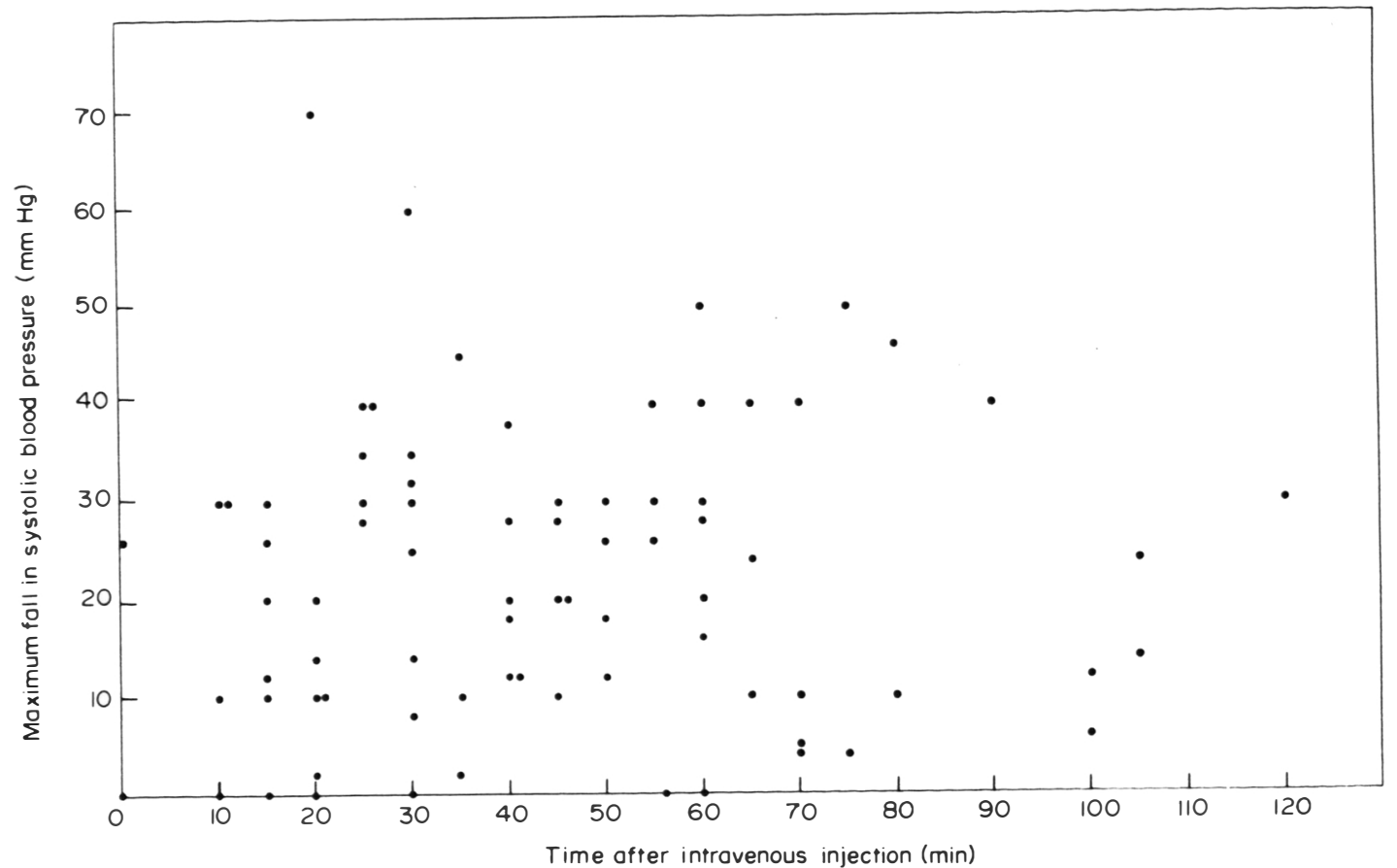

Fig. 2. Scattergram to show the relation between the time taken for the maximum fall in blood pressure to occur and the size of that fall. 


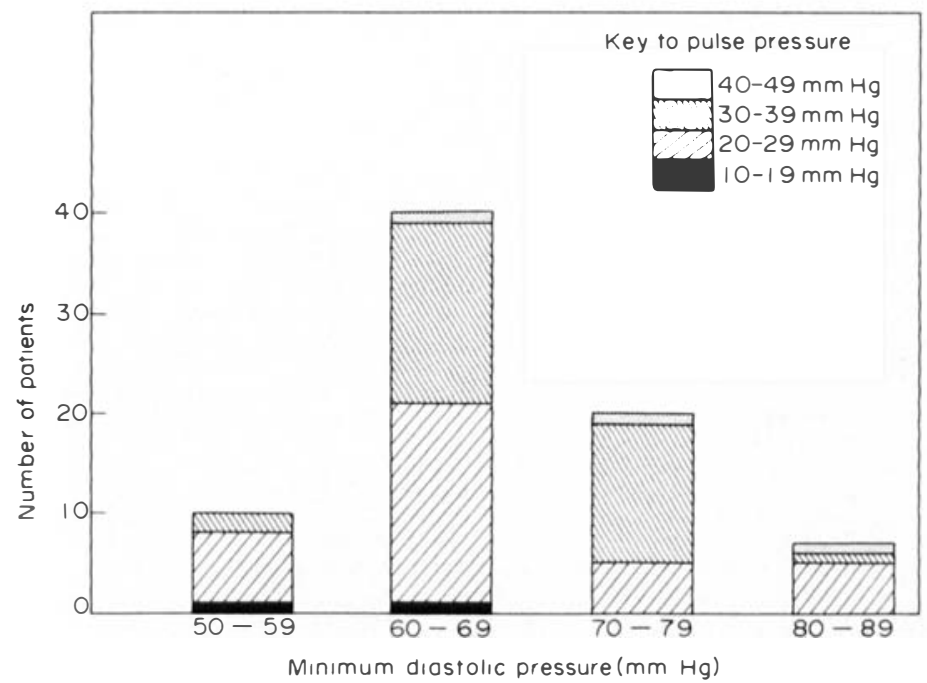

Fig. 3. Distribution of the pulse pressure correlated with the minimum diastolic pressure.

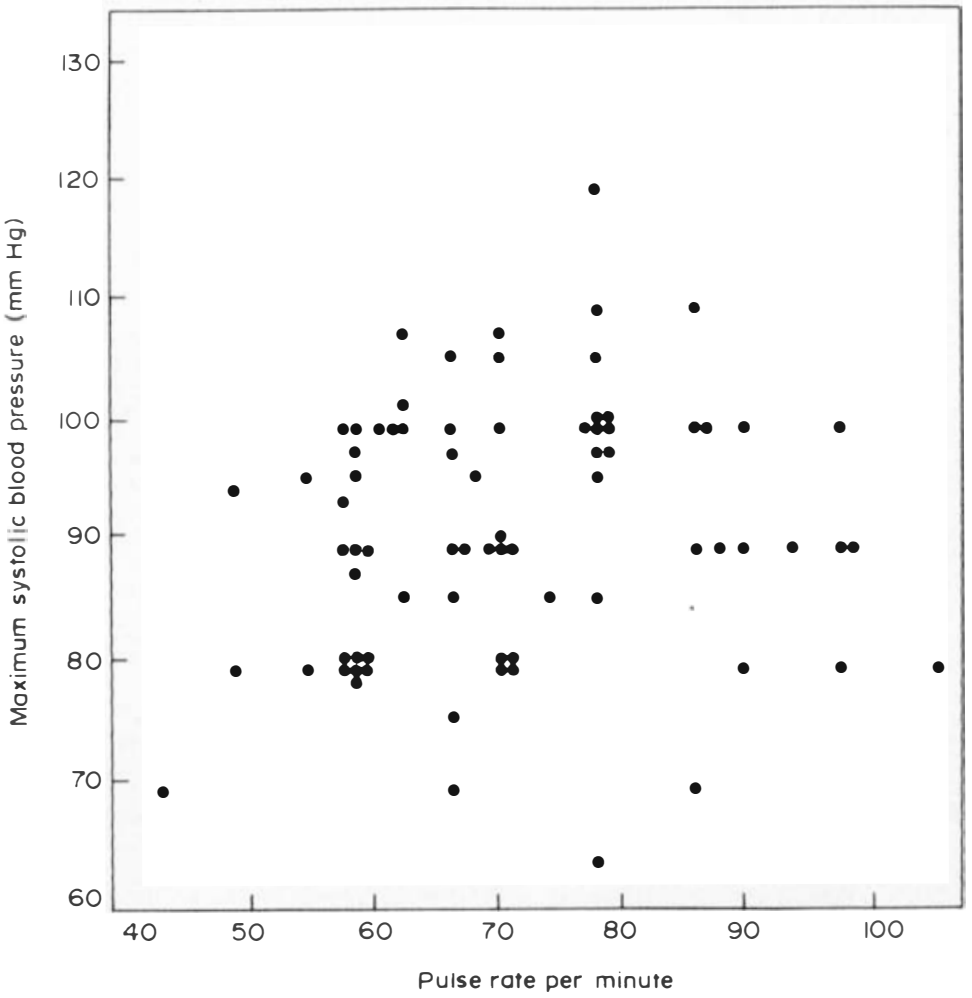

Fig. 4. Scattergram to show the relation between the minimum systolic blood pressure and the pulse rate. 
respiratory rate fall below 10 per min, nor did any patients become cyanosed. We consider that the respiratory rate is a good guide to the safety of giving a supplementary dose of cocktail should this become necessary. This should not be given if the rate falls to below 10 per min; rather, oxygen should be given until the rate has returned to normal. Since tone of the jaw muscles is maintained, no airway or jaw support is usually required; it is found that simple posturing is adequate to maintain an adequate airway. In a few patients undergoing operations on the head or neck, a rubber airway was well tolerated.

\section{HYDRATION EFFECTS}

We do not routinely give intravenous fluids during or after operation. All patients are admitted to hospital for at least $36 \mathrm{~h}$ before operation; adequate hydration can therefore be achieved in this period, and fluids are given by mouth as soon as the patient is able to take them. Dehydration has rarely been scrious during or after the operation, even during the humid heat of summer. However, it is not advisable to use this type of anaesthesia for patients who are already suffering from oligaemic shock or in whom marked blood loss is expected.

\section{ENVIRONMENTAL EFFECTS}

Most of the patients in this series were operated on in summer and in an air-conditioned theatre. This probably saved them from the consequences of reflex vasodilatation which may occur in a non-air-conditioned theatre: this effect is accentuated by the heat conserved by coverings and also that of the theatre lamp.

\section{OTHER EFFECTS}

Because the reflexes are maintained, external stimuli may cause rapid fluctuations in pulse and blood pressure. This was noticed when the patient complained of discomfort because of the pressure of the tourniquet, or during the more painful procedures of the operation, or in being moved to the ward. Patients frequently become restless after about $1 \mathrm{~h}$, but once the tourniquet is released they soon become quiet and relaxed. If the tourniquet has to be reapplied, patients usually tolerate the pressure for half to three-quarters of an hour before needing further intravenous medication. This may indeed be given, but the patient may lapse into a prolonged heavy sleep.

\section{Comments}

\section{USES}

Cocktail Anaesthesia can be used in many situations where there is a staff shortage and yet surgery needs to be performed. Supplementation with local anaesthesia makes it suitable for procedures such as thyroidectomy and simple abdominal procedures, where full muscle relaxation is not required. It is ideal for minor operations on the hand or foot, such as curettage of abscesses or sinuses.

\section{DISADVANTAGES}

The interval between the injection and the attainment of the required level of analgesia is variable. Since patients retain deep reflexes, spasmodic muscle movements may occur if nerves are stimulated. This does not however indicate that the patient feels pain. 


\section{References}

Brand, P. W. (1964). Deformity in leprosy. In Leprosy in Theory and Practice, 2nd ed., p. 483. (kids R. (i. Cochrane and T. I. Davey). Bristol: John Wright \& Sons L.td.

Fritschi, E. P. (1971). Reconstructive Surgery in Leprosy, pp. 2, 204. Bristol: John Wright \& Sons Ltd. 